\title{
STRATEGI DALAM MENINGKATKAN LITERASI KEUANGAN MELALUI PRODUK PERBANKAN UNTUK WARGA RT 006/RW 10, KAMPUNG CIMUNCANG, DESA KARANGNUNGGAL, TASIKMALAYA, JAWA BARAT
}

\author{
Rizka Wahyuni Amelia, Widya Intan Sari, Lina Nofiana, Arif Hidayat, Asep \\ Muhammad Lutfi, Muhamad Randy Akbar \\ Universitas Pamulang \\ Email:dosen02465@unpam.ac.id
}

\begin{abstract}
People who are well literate more easily understood hal-hal related to financial services industry as well as have the information to access financial services industry is required in the activity of the life of seharihari them. This allows them more easily in determining products and services financial services according to the needs and the capacity in order to increase welfare. addition, literate people well tend to have have a better financial management capabilities in support of their financial welfare. The, on the the existing problems in resident of $r t 006 r w / 10$, their cimuncang, village, karangnunggal tasikmalaya, west java is the lack of financial literasi not for the area has been held to socialize financial literasi. The solution of we as the manager of tridharma college is give the understanding of concerning the improvement of financial products literasi through perbankan.sehingga resident of rt 006 / rw 10 , their cimuncang , karangnunggal village, tasikmalaya, west java further is expected to encourage increase the use of products and services financial appropriate to their needs to to lift community economic. The target outer we will reach is so that the people $r t 006 / r w 10$, their cimuncang, karangnunggal village, tasikmalaya, west java can know how ways to improve literasi financial especially to the product banking, indonesian products banking know that is that fore is expected to utilize them in accordance with the needs of especially in develops UKM (small and medium enterprises).
\end{abstract}

Keywords: Literasi financial, Banking products, UKM

\begin{abstract}
Abstrak
Masyarakat yang well literate lebih mudah memahami hal-hal yang terkait dengan industri jasa keuangan serta memiliki informasi untuk mengakses industri jasa keuangan yang diperlukan dalam aktivitas kehidupan seharihari mereka. Hal tersebut memungkinkan mereka lebih mudah dalam menentukan produk dan layanan jasa keuangan yang sesuai dengan kebutuhan dan kemampuan dalam upaya meningkatkan kesejahteraan. Di samping itu, masyarakat yang well literate cenderung memiliki kemampuan pengelolaan keuangan yang lebih baik dalam mendukung kesejahteraan keuangan mereka. Berdasarkan hal tersebut, permasalahan yang ada di Warga RT 006/RW 10, Kampung Cimuncang, Desa Karangnunggal,
\end{abstract}


Tasikmalaya, Jawa Barat adalah kurangnya literasi keuangan disebabkan didaerah tersebut belum pernah diadakan sosialisasi terkait literasi keuangan. Solusi dari kami sebagai Pelaksana Tridharma Perguruan Tinggi adalah Memberikan pemahaman tentang peningkatan literasi keuangan melalui produk-produk perbankan.Sehingga warga RT 006/RW 10, Kampung Cimuncang, Desa Karangnunggal, Tasikmalaya, Jawa Barat lebih lanjut diharapkan mampu mendorong peningkatan pemanfaatan produk dan jasa keuangan yang sesuai dengan kebutuhan mereka guna untuk mengangkat ekonomi masyarakat. Target luaran yang kami akan capai adalah agar Warga RT 006/RW 10, Kampung Cimuncang, Desa Karangnunggal, Tasikmalaya, Jawa Barat dapat mengetahui bagaimana cara meningkatkan literasi keuangan terutama dengan produk perbankan, mengetahui produk-porduk perbankan yang ada agar kedepan diharapkan dapat memanfaatkannya sesuai dengan kebutuhan terutama dalam mengembangkan UKM (usaha kecil menengah).

Kata Kunci: Literasi Keuangan, Produk Perbankan, UKM

\section{A. PENDAHULUAN}

Desa Karangnunggal secara administrasi berada di wilayah Kecamatan Karangnunggal Kabupaten Tasikmalaya. Provinsi Jawa Barat. Desa Karangnunggal termasuk katagori Desa lama,karena keberadaannya telah ada dan diakui jauh sebelum Pemerintah Kabupaten Tasikmalaya dibentuk dan di sahkan dengan UU No 14 tahun 1950. Posisi geografis Desa Karangnunggal berada di sebelah selatan Kabupaten Tasikmalaya,Provinsi Jawa Barat dan terletak antara $7^{\circ}, 37^{\prime} 844^{\prime \prime}$ LS dan $108^{\circ}$ '07'973" BT dengan ketinggian +947 kaki = 266,3 M dpl,luas wilayah Desa Karangnunggal adalah 952,769 Ha ( 9,52 Km2) atau 13,45 \% dari total luas wilayah Kecamatan Karangnunggal sebesar 128.210Ha. Desa Karangnunggal dibentuk sejak jaman penjajahan Belanda, dan diberi nama Karangnunggal yang diambil dari nama sebuah kandungan air laut yakni : Karang, Karang adalah jenis batu-batuan di laut yang mempunyai kekuatan dan mampu bertahan di terjang ombak (dalam bahasa sunda Bedas). Nunggal adalah asal kata dari tunggal yang berarti satu (Bersatu). Dengan dinamakan Karangnunggal mempunyai sebuah harapan yang sangat berharga bahwa masyarakat Desa Karangnunggal akan mampu mempererat hubungan persaudaraan ,meningkatnya persatuan dan kesatuan dalam mempertahankan segala macam tantangan dan hambatan dari segala aspek yaitu Ideologi, Poltik, Ekonomi, Sosial, Budaya dan Pertahanan Kemanan rakyat semesta.

Terbentuknya suatu Pemerintahan Desa Karangnunggal secara administrasi belum diperoleh data yang tepat dan pasti,akan tetapi sejak jaman penjajahan Belanda Pemerintahan Desa Karangnunggal telah berfungsi sesuai peraturan yang berlaku di saat masa-masa pemerintahan Negara Kesatuan Republik Indonesia sebelum merdeka.

Nama-nama yang telah menjadi Kepala Desa :

1. Jaman Penjajahan Belanda adalahSujaya

2. Setelah merdeka adalahAdiwinata

3. Pada tahun $1955 \mathrm{~s} / \mathrm{d}$ tahun 1965 adalahKartaatmaja

4. Pada tahun 1966s/d tahun 1975 adalah IdohSapri

5. Pada tahun $1976 \mathrm{~s} / \mathrm{d}$ tahun 1980 adalah IyusRustijan

6. Pada tahun $1981 \mathrm{~s} / \mathrm{d}$ tahun 1989 adalah AcengSukarsa 
7. Pada tahun $1990 \mathrm{~s} / \mathrm{d}$ tahun 1998 adalahH.Osi

8. Pada tahun $1998 \mathrm{~s} / \mathrm{d}$ tahun 2006 adalahTisnawa

9. Pada tahun $2007 \mathrm{~s} / \mathrm{d}$ tahun 2013 adalah Drs. TatangBachtia

Nama yang sedang menjabat Kepala Desa Karangnunggal:

1. Dana Wardiana Tasikmalaya 10-08-1962 SLAKepalaDesa

2. Sandi SuardiTasikmalaya 01-10-1973 SLA SekretarisDesa

3. Nunung Nuryani Tasikmalaya 12-12-1970 SLA Kaur Keuangan

4. Riono Tasikmalaya 07-11-1964 SLA KaurPerencanaan

5. Cecep Irvan Tasikmalaya 03-07-1984 SMU Kaur Tata Usaha

6. Iwan Tasikmalaya 03-02-1973 SLPKasi Kesejahteraan

7. Asep Sopyan Tasikmalaya 17-01-1974 SLA Kasi Pelayanan

8. Rahmat Budiara Tasikmalaya 09-11-1965 SLTA Kasi Pemerintahan

9. CepiRosadi Tasikmalaya 10-11-1975 SLA Kepala Dusun Kr.nunggal

10. DedeRohidin Tasikmalaya 30-06-1971 SD Kepala Dusun Karangsari

11. OkaSomantri Tasikmalaya 05-04-1970 SLA Kepala Dusun Ciawitali

12. Rohmat Tasikmalaya 23-06-1967 SLA Kepala Dusun Cimuncang

13. Heryat Tasikmalaya 19-05-1965 SLA Kepala Dusun Mekarsari

14. YudinTasikmalaya 02-01-1969 SD Kepala Dusun Rahayu

15. Aji Tasikmalaya 07-06-1979 SD Kepala Dusun Cikadu

Batas-batas wilayah Desa Karangnunggal adalah :

Sebelah Utara : Desa Karangmekar

Sebelah Timur : Desa Cibatuireng

Sebelah Selatan : Desa Cikupa dan Desa Ciawi

Sebelah Barat : Desa Hegarwangi Kecamatan Bantarkalong

Wilayah administrasi desa Karangnunggal terbagi dalam beberapa kedusunan, yaitu:

Kedusunan Karangnunggal terbagi dalam 2 RW dan 7 RT

Kedusunan Karangsari terbagi dalam 2 RW dan 8 RT

Kedusunan Ciawitali terbagi dalam 1 RW dan 7 RT

Kedusunan Cimuncang terbagi dalam2 RW dan 10 RT

Kedusunan Mekarsari terbagi dalam 2 RW dan 8 RT

Kedusunan Rahayuterbagi dalam 2 RW dan 6 RT

Kedusunan Cikadu terbagi dalam 1 RW dan 7 RT

\section{Profil Dusun Cimuncang}

Dusun Cimuncang dibentuk setelah terbentuknya Pemerintahan Desa Karangnunggal, dan diberi nama Cimuncang adalah diambi dari kata Cai yang disingkat menjadi Ci (bahasa sunda) = Air (bahasa Indonesia) dan Muncang (bahasa sunda) $=$ Kemiri ( bahasa Indonesia) $\mathrm{Ci}$, Cai $=$ Air adalah merupakan salah satu sumber kehidupan dan kebutuhan primer bagi semua mahluk hidup. Muncang $=$ Kemiri adalah jenis kayu hutan yang tumbuh subur dan berbuah lebat, kemudian buahnya bermanfaat untuk bumbu masak, dan konon kabarnya di kampung tersebut ada setangkai pohon Muncang/Kemiri yang besar dan kokoh sehingga keberadaannya menghasilkan sumber air dan sangat menunjang terhadappeningkatan hasil produksi pertanian. 
Jadi : dengan dinamakan Cimuncang mempunyai makna " kampung yang subur akan kandungan alam disertai kekuatan budaya kebersamaan dalam melaksanakan pembangunan Nasional “.

Kami memilih dusun Cimuncang pada kegiatan Pengabdian Kepada Masyarakat ini adalah karena salah satu rekan kami berasal dari daerah tersebut, dan menurutnya warga didaerah tersebut kurangnya pemahaman tentang literasi keuangan. Pihak Tokoh Masyarakat di daerah tersebut bersedia menyediakan tempat dan sarana untuk terlaksananya Program Pengabdian Kepada Masyarakat di tempat tersebut. Kami merasa sangat perlu membagikan ilmu yang kami punya tentang literasi keuangan, karena kami merupakan lulusan Master manajemen yang berbasic keuangan dan kami mengajar mata kuliah keuangan di Universitas Pamulang.

\section{B. METODE PELAKSANAAN KEGIATAN}

Berdasarkan analisa situasi yang telah dipaparkan, dapat disimpulkan beberapa permasalahan Warga RT 006/RW 10, Kampung Cimuncang, Desa Karangnunggal, Tasikmalaya, Jawa Barat. Solusi atas permasalahan kurangnya pegetahuan Warga RT 006/RW 10, Kampung Cimuncang, Desa Karangnunggal, Tasikmalaya, Jawa Barat dapat mengetahui bagaimana cara meningkatkan literasi keuangan adalah:

1. Sosialisasi cara meningkatkan literasi keuangan, apa saja fungsi literasi keuangan dan cara mengelola keuangan yang baik serta memberikan gambaran bagaimana membuat perencanaan keuangan yang tepat bagaimana memanajemen keuangan hingga memecahkan masalah perencanaan keuangan kedepan agar lebih baik.

2. Simulasi produk-produk perbankan yang ada, perlu sekali mengetahui manfaat serta resiko yang acap kali timbul dari produk perbankan agar dapat tercapai perencanaan keuangan dengan pengelolaan yang tepat.

3. Edukasi tentang nilai mata uang yang berfluktuasi.

4. Edukasi tentang investasi agar masyarakat tidak sembarang dalam menenamkan uang.

5. Edukasi tentang mengembangkan UKM (usaha kecil menengah) guna mengangkat ekonomi masyarakat.

Metode kegiatan yang digunakan adalah bekerjasama dengan warga RT 006/RW 10, Kampung Cimuncang, Desa Karangnunggal, Tasikmalaya, Jawa Barat agar warga mendapatkan pengetahuan tentang literasi keuangan.

Langkah-langkah yang kami tempuh untuk melaksanakan solusi atas permasalahan yang dihadapi Warga RT 006/RW 10, Kampung Cimuncang, Desa Karangnunggal, Tasikmalaya, Jawa Barat adalah :

1. Melakukan pelaksanaan kegiatan Pengabdian Kepada Masyarakat secara Online dimulai pada tanggal 4 April 2020 pukul 10.00 WIB sampai dengan selesai target khalayak pada warga Kampung Cimuncang RT 006/RW 10, Desa Karangnunggal, Tasikmalaya.

2. Pelaksanaan kegiatan Pengabdian Kepada Masyarakat secara Online dimulai kembali pada tanggal 5 April 2020 pukul 10.00 WIB sampai dengan selesai, agar warga Kampung Cimuncang RT 006/RW 10, Desa Karangnunggal, Tasikmalaya dapat lebih memahami materi yang disampaikan.

3. Memperkenalkan diri kami sebagai pelaksana kegiatan program Pengabdian kepada Masyarakat " STRATEGI DALAM MENINGKATKAN LITERASI KEUANGAN MELALUI PRODUK PERBANKAN UNTUK WARGA RT 006/RW 10, 
KAMPUNG CIMUNCANG, DESA KARANGNUNGGAL, TASIKMALAYA, JAWA BARAT" dan ramah tamah dengan warga setempat.

4. Waktu pelaksanaan kegiatan tanggal 4 April 2020 dimulai pukul 10.00 WIB sampai dengan selesai. Memberikan pengetahuan umum tentang tentang literasi keuangan.

5. Waktu pelaksanaan kegiatan tanggal 4 April 2020 dimulai dari pukul 10.00 WIB sampai dengan selesai. Simulasi produk-produk perbankan yang ada.

6. Waktu pelaksanaan kegiatan tanggal 4 April 2020 dimulai dari pukul 10.00 WIB sampai dengan selesai. Edukasi tentang nilai mata uang yang berfluktuasi.

7. Waktu pelaksanaan kegiatan tanggal 5 April 2020 dimulai dari pukul 10.00 WIB sampai dengan selesai. Edukasi tentang investasi agar masyarakat tidak sembarang dalam menenamkan uang.

8. Waktu pelaksanaan kegiatan tanggal 5 April 2020 dimulai dari pukul 10.00 WIB sampai dengan selesai. Edukasi tentang mengembangkan UKM (usaha kecil menengah) guna mengangkat ekonomi masyarakat.

9. Waktu pelaksanaan kegiatan tanggal 5 April 2020 dimulai dari pukul 10.00 WIB sampai dengan selesai. Penutupan dan berpamitan serta ucapan terima kasih kepada warga dan tokoh masyarakat yang turut hadir dalam forum daring/online.

10. Waktu pelaksanaan kegiatan tanggal 5 April 2020 dimulai dari pukul 10.00 WIB sampai dengan selesai.

\section{HASIL DAN PEMBAHASAN}

\section{Tahap Persiapan}

Kegiatan PKM yang dilaksanakan dengan cara daring/online dengan memanfaatkan teknologi dan internet yang ada dapat berjalan dengan baik dan lancar. Pertemuan dengan cara daring/online ini dengan metode ceramah dan demonstrasi, dilanjutkan latihan/praktek untuk membuat media pembelajaran, mulai dari pemilihan materi, penyusunan, pemilihan huruf, pemberian efek dan animasi dan tampilan. Kegiatan ini dilaksanakan 2 (dua) hari yaitu pada hari Sabtu dan Minggu pada tanggal 4 April 2020 dan 5 April 2020. Peserta kegiatan berjumlah sekitar kurang lebih 10 (sepuluh) orang warga berikut 2 (dua) orang tokoh masyarakat.

Pelaksanan kegiatan PKM ini dilakukan oleh 5 (lima) orang tim pengabdi dengan pokok bahasan yang disampaikan mengenai: 1. Teori media pembelajaran 2 . Pengembangan media pembelajaran yang layak 3. Langkah-langkah penyusunan dan pengembangan media pembelajaran berbasis komputer 4. Latihan pembuatan media pembelajaran 5. Evaluasi hasil media pembelajaran yang telah disusun.

Semua materi dapat disampaikan dengan detil. Kegiatan yang diawali dengan ceramah dan demonstrasi ini kemudian dilanjutkan latihan. Acara kemudian dilanjutkan sesi tanya jawab. Berbagai pertanyaan diajukan secara antusias oleh para peserta dalam sesi tanya jawab. Program pengabdian pada masyarakat berupa pembinaan dan pengetahuan sebagai perbekalan guna mengangkat perekonomian serta kesejahteraan masyakarat. Warga akan lebih semangat dan termotivasi untuk mengembangkan diri. Hasil pembinaan dan pengetahuan ini akan bermanfaat bagi warga itu sendiri. Disamping itu dengan adanya pembinaan dan pengetahuan ini akan menambah keterampilan warga dalam menyejahterakan kehidupan nantinya.

\section{Tahap Pelaksanaan Pengabdian Kepada Masyarakat}

Tempat pelaksanaan kegiatan Pengabdian Kepada Masyarakat ini adalah : Warga Rt 006 Rw 10 Kampung Cimuncang, Desa Karangnunggal Tasikmalaya, Jawa Barat. 
Waktu pelaksanaan kegiatan Pengabdian Kepada Masyarakat ini adalah : 04-05 April 2020.Karena saat ini sedang ada pandemi Covid-19 maka dari itu pelaksanaan kegiatan Pengabdian Kepada Masyarakat ini dilakukan secara daring/online dengan memanfaatkan teknologi dan internet.

\section{Tahap Pelatihan}

Untuk melaksanakan kegiatan tersebut digunakan beberapa metode pelatihan yaitu:

a. Metode ceramah

Metode yang digunakan dalam pemaparan materi pertama tentang mengembangkan UKM (usaha kecil menengah) disampaikan oleh ketua PKM Ibu Rizka Wahyuni Amelia, S.E., M.M., sekaligus sebagai moderator. Selanjutnya pemaparan materi inti disampaikan oleh empat orang dosen dari tim PKM UNPAM. Pertama Bapak Asep Muhammad Lutfi, S.E., M.M., C.STMI. menyampaikan materi dengan memberikan pengetahuan umum tentang tentang literasi keuangan. Kedua Bapak Arif Hidayat, S.E.,M.M. menyampaikan materi tentang bagaimana simulasi produk-produk perbankan yang ada, ketiga Ibu Widya Intan Sari, S.E.,M.M. membuat konten promosi yang mudah di ingat tentang investasi agar masyarakat tidak sembarang dalam menanamkan uang dan keempat materi disampaikan oleh Ibu Lina Nofiana, S.E.,M.M. yang memberikan rangkuman kesimpulan terhadap pemaparan materimateri yang telah disampaikan.

b. Metode tanya jawab

Setelah sesi ceramah sudah selesai, maka dilanjutkan dengan sesi tanya jawab. Hasilnya, peserta sangat antusias untuk menanyakan bagaimana cara mengembangkan UKM (usaha kecil menengah), menanamkan uang, serta produk-produk perbankan yang ada.

c. Metode simulasi

Pelatihan ini juga diberikan metode simulasi, sehingga peserta langsung dapat mempraktekan apa yang sudah disampaikan. Apabila ada kendala maka langsung dibantu pada saat pelaksanaan PKM. Simulasi penting dilakukan untuk mengetahui seberapa besar tingkat pengetahuan dan ilmu yang diserap pada saat pelatihan.

\section{KESIMPULAN DAN SARAN}

\section{Simpulan}

Program pengabdian pada masyarakat berupa pembinaan untuk memberikan pengetahuan tentang sosialiasi cara meningkatkan literasi keuangan, simulasi produk perbankan, edukasi tentang nilai mata uang yang berfluktuatif, edukasi tentang investasi agar masyarakat tidak sembarang dalam menenamkan uang, edukasi tentang mengambangkan UKM (usaha kecil masyarakat) guna untuk mengangkat ekonomi serta kesejahteraan masyarakat terutama Warga RT 006/RW 10, Kampung Cimuncang, Desa Karangnunggal, Tasikmalaya, Jawa Barat. Solusi atas permasalahan kurangnya pegetahuan Warga RT 006/RW 10, Kampung Cimuncang, Desa Karangnunggal, Tasikmalaya, Jawa Barat. Kegiatan ini mendapat sambutan sangat baik terbukti dengan keaktifan peserta mengikuti pendampingan secara daring/online dengan tidak meninggalkan tempat sebelum waktu pembinaan dan implementasi berakhir.

\section{Saran}

Berdasarkan evaluasi yang telah dilakukan dapat diajukan beberapa saran sebagai berikut: 1 . Waktu pelaksanaan kegiatan pengabdian perlu ditambah agar tujuan kegiatan dapat tercapai sepenuhnya, tetapi dengan konsekuensi penambahan biaya pelaksanaan. 
Oleh karena itu biaya PKM sebaiknya tidak sama antara beberapa tim pengusul proposal, mengingat khalayak sasaran yang berbeda pula. 2. Adanya kegiatan lanjutan yang berupa pelatihan sejenis selalu diselenggarakan secara periodik sehinga dapat meningkatkan perekonomian dan kesejahteraan masyarakat.

\section{Ucapan Terima Kasih}

Rasa syukur dan suka cita kamu haturkan kepada segenap pihak yang telah mensukseskan kegiatan PKM dengan judul "STRATEGI DALAM MENINGKATKAN LITERASI KEUANGAN MELALUI PRODUK PERBANKAN UNTUK WARGA RT 006/RW 10, KAMPUNG CIMUNCANG, DESA KARANGNUNGGAL, TASIKMALAYA, JAWA BARAT" kepada:

1. Rektor Dr. H. Dayat Hidayat, M.M, Rektor Universitas Pamulang Tangerang Selatan Banten.

2. Dr. Ali Maddinsyah, S.E., M.M., selaku Ketua LPPM Universitas Pamulang Tangerang Selatan - Banten.

3. Dr. Kasmad, S.E., M.,M., selaku Ketua Program Studi Manajemen Universitas Pamulang Tangerang Selatan - Banten.

4. Dr. Udin Ahidin, S.E., M.M., C.M.A, Selaku Wakil Program Studi Manajemen Universitas Pamulang Tangerang Selatan - Banten.

5. Drs. Waluyo Jati, M.M., Selaku Sekretaris Program Studi Manajemen Universitas Pamulang Tangerang Selatan - Banten.

6. Bapak Suhendar, selaku Pimpinan Kepala Dusun Kampung Cimuncang Desa Karangnunggal-Tasikmalaya, Jawa Barat.

7. Seluruh warga RT. 006/RW.10 Kampung Cimuncang Desa Karangnunggal-Tasikmalaya, Jawa Barat.

8. Mahasiswa Universitas Pamulang yang juga ikut berkontribusi terhadap kelancaran kegiatan PKM.

\section{DAFTAR PUSTAKA}

Tomaskova. H, et.al. (2011). Issues of financial literacy education. Procedia -Social and Behavioral Sciences 28 (2011) 365-369

Chen, H \& Volpe, R.P. (2002). Gender Differences in Personal Literacy Among College Students. Financial Services Review 11. p289-307

Lusardi, A, et.,al. (2010). Financial Literacy Among the Young, Journal of Consumer Affairs. 44(2), pp 358-380.

Solihin, D. (2020), Pengaruh Kepercayaan Pelanggan dan Promosi Terhadap Keputusan Pembelian Konsumen Pada Online Shop Mikaylaku Dengan Minat Beli Sebagai Variabel Intervening. JURNAL MANDIRI: Ilmu Pengetahuan, Seni, dan Teknologi, Vol. 4, No. 1.

Solihin, D. (2020), Faktor-Faktor yang Mempengaruhi Kinerja Pemasaran Pada PT. Prima Ufuk Semesta Studi Pada Outlet Rekanan PT. Prima Ufuk Semesta di Wilayah JABODETABEK, Jurnal Semarak, Vol. 3 No.1.

Solihin, D. (2020), Pengaruh Kualitas Pelayanan, Harga, Dan Promosi Terhadap Keputusan Pelanggan Dalam Memilih Klub Basket Satria Indonesia Tangerang Selatan, Jurnal Pemasaran Kompetitif, Vol. 3, No. 3.

Solihin, D. (2019), Pengaruh Current Ratio dan Debt to Equtity Ratio Terhadap Return on Asset (ROA) Pada PT. Kalbe Farma Tbk. Jurnal Kreatif, Vol. 7. No. 1. 